\section{$\$$ Research Square}

Preprints are preliminary reports that have not undergone peer review.

They should not be considered conclusive, used to inform clinical practice, or referenced by the media as validated information.

\title{
Energy Reduction with Application of Shaft in Water Supply Systems
}

\section{Anujkumar Ghorpade}

Indian Institute of Technology Bombay

Abhishek kumar Sinha

Indian Institute of Technology Bombay

Pradip Kalbar ( $\sim$ kalbar@iitb.ac.in )

Indian Institute of Technology Bombay https://orcid.org/0000-0002-1436-3609

\section{Research Article}

Keywords: Break pressure tank, Energy efficiency, Developing nation, Shaft, Water transmission network, Water hammer

Posted Date: December 17th, 2021

DOI: https://doi.org/10.21203/rs.3.rs-1174501/v1

License: (c) (i) This work is licensed under a Creative Commons Attribution 4.0 International License. Read Full License 


\section{Abstract}

A Water Transmission Network (WTN) conveying raw water from a source to the Water Treatment Plant (WTP) is often pumped supply. Pumped supply-based networks have more energy consumption, water hammer, and high operation and maintenance compared to gravity systems. The present study reports the application of a Shaft in WTN for improving the efficiency of the pumping system. The Shaft is a hydraulic isolation structure based on a similar hydraulic principle as Break Pressure Tank (BPT). The benefits of using Shaft are quantified based on the two case studies from Maharashtra, India. The impact of Shaft on the WTN is reported using energy grade lines, energy performance indicators, and life cycle energy cost. In addition to the reduction in energy consumption, from the case studies, it is shown that the system's carrying capacity could be increased by using the Shaft at an appropriate location in WTN. Overall, a Shaft provides operational flexibility to the operators, improving the efficiency of the system.

\section{Introduction}

A Water Supply System (WSS) comprises a combination of pipelines, tanks, valves, and pumps. In India, a pipeline network conveying water from a surface water source to a Water Treatment Plant (WTP) and from WTP to Storage Tank (ST) is termed as Water Transmission Network (WTN) (CPHEEO 1999). Beyond ST, the pipeline network until the consumer end is termed Water Distribution Network (WDN). Depending on the topography, the WTN between the water source and WTP is called Raw Water Gravity Main (RWGM) or Raw Water Pumping Main (RWPM). As the quantity of water to be transported is enormous, large diameter pipelines are required for RWGM or RWPM. In most of the WSSs in India, RWPM is required to fetch water from a source to WTP. The requirement of pumps to convey water in a WSS results in significant energy consumption (Coelho and Campos 2014). The energy consumption is directly related to the cost of operation of a WSS. Energy consumption cost contributes around $80 \%$ of the total operational cost of a WSS (Zaman et al. 2021).

Many studies have reported methods to quantify the energy consumption of a WSS (Pelli and Hitz 2000; Cabrera et al. 2010). Additionally, studies have also focused on the application of probable interventions like variable speed pumps, Pumps-As Turbines (PAT), and Pressure Reducing Valves (PRVs) to improve the energy efficiency of WSS (Carravetta et al. 2012; Fecarotta et al. 2015; del Teso et al 2019).

Cabrera et al. (2015) have proposed three indicators to access the energy efficiency of a WSS. Based on the proposed indicators, the actual performance and the maximum achievable efficiency of a WSS can be determined. Also, authors developed a framework to improve the energy efficiency of a WSS. The proposed framework was tested on a real case study, resulted in significant energy savings.

A pumped piped network results in more wear and tear than a gravity-based system due to transitional pressures (Zaman et al. 2021), and water hammer is the primary problem responsible for the deterioration (Bohorquez et al. 2020). Numerous studies have reported the theory of water hammer and solution to minimize its impact on the network (Boulos et al. 2005; Nault and Karney 2016; Wan and Zhang 2018). 
The work of Miao et al. (2017) provides a new surge protection measure using a combination of air vessels and a control valve to suppress the effect of a water hammer. The authors were able to reduce the volume of air vessel as well as water hammer protection simultaneously.

A Break Pressure Tank (BPT) is considered one of the solutions to minimize the impact of a water hammer (Sontake et al. 2016). In a BPT, the pressurized water flow is allowed to discharge into the atmosphere, resulting in energy dissipation and setting up a new Hydraulic Grade Line (HGL) (Jordon 1984). Application of BPT in WSS results in a reduction in static head over the pipeline without compromising the intended flow, ultimately improving the efficiency of the network (Bajwa 2011). Although the concept of BPT has been known for a while, limited studies suggest a lack of complete utilization of the benefits of a BPT. McNabola et al. (2011) proposed a method for energy recovery from BPT. A turbine was proposed upstream of the BPT to recover the dissipated energy. A case study from Ireland was considered, and substantial energy saving was possible using the proposed modification in the BPT. Kalbar and Gokhale (2019) recently introduced Shaft, a hydraulic isolation structure applicable in both WTN and WDN. Even though the working principle of Shaft is similar to BPT, the size, construction material, configuration, and utility of Shaft are different compared to BPT.

The studies regarding the application of Shaft in WSS are missing in the literature. The present study reports the use of Shaft in WTN between source and WTP in the state of Maharashtra, India, to fulfill the knowledge gap. The benefits of Shaft in the WTN are quantified using energy performance indicator and life cycle cost of pumping energy. Also, the overall impact of Shaft in WTN is described. The introduction is followed by the methodology used in the study, then the results and discussion are reported. In the end, the conclusions and future scope of work are discussed.

\section{Methodology}

In the present study, two case studies (Bhima river WSS, Solapur, and Pise weir WSS, Thane) from Maharashtra, India, were considered to evaluate the performance of Shaft in the WTN (refer to Fig. S1). Shaft in the WTN is used to overcome the ground undulations and convert the RWPM to RWGM. Additionally, the Shaft construction at an appropriate location in WTN impacted the system's carrying capacity in both the case studies. The change in carrying capacity was captured with the help of the Total Energy Line (TEL) and Hydraulic Gradient Line (HGL). Bernoulli's theorem is used for the calculation of TEL and HGL. Bernoulli's theorem states that in a steady, ideal flow of an incoming pressurized fluid, the total energy is constant at any point of the fluid. The total energy comprises kinetic energy and potential energy or datum energy (Bansal 2011). The energies per unit weight of the fluid and the mathematical formulation of Bernoulli's theorem are mentioned in Supplementary Information (SI) (equation 1). Due to viscosity, resistance in the flow is encountered for the real fluids, resulting in loss of energy. The frictional loss is the significant component of total losses, as shown in Fig. S2.

Shaft is a vertical hollow cylinder with one inlet and can have multi outlet as per requirement (Fig.1a). Water from the inlet spills into the hollow section and creates a water column. As water spills into the 
hollow section, the HGL from the upstream end gets disconnected, and a new HGL is established based on the water level in the hollow section. Hence, a Shaft acts as a hydraulic separator between the upstream and downstream pipeline. Recently, a Shaft was commissioned at Saphale, Palghar, Maharashtra, India, to improve the efficiency of the distribution in terms of pressure and equity (Fig.1b). Kalbar et al. (2021) have reported the impact of Shaft on the distribution network.

In WTN, the hydraulic barrier created through the Shaft helps to convert the RWPM to RWGM. Also, as the inlet of the Shaft is open to the sky, the entrapped air in the RWPM gets expelled, nullifying the water hammer effect. The water column formed in the hollow section governs the hydraulics of the downstream side, and water from the Shaft is transported under gravity.

As Shaft converts the RWPM to RWGM, and the operational energy of the system gets modified. The Specific Energy Consumption (SEC), one of the Energy Performance Indicators (EPI) reported in Zaman et al. 2021, was used to quantify the impact of Shaft on the operational energy of the system (Fig. 2). The mathematical formulations for the pump's power requirement and Hazen-Williams formula determining head loss and SEC are reported in SI (equations 2, 3, and 4). Furthermore, the energy cost of the WTN for the 30 years' design period was calculated (Fig. 2). Life cycle energy cost was calculated based on the principle reported in CWC (2017). The present worth of the energy cost was calculated using equations 5 and $6(\mathrm{SI})$. Also, the cash flow diagram considered for calculating the present worth of energy cost is depicted in Fig. S3. The information regarding the WTN from both case study areas was collected through site visits and interaction with the field engineers. Details about each case study are discussed below.

\subsection{Case Study 1: Shaft at Bhima river Water Supply Scheme, Solapur, Maharashtra, India}

Solapur city is located in the south-western region of the state of Maharashtra, India. The total administrative boundary of the city results in $180 \mathrm{sq} . \mathrm{km}$. of area. The Bhima river, situated around $30 \mathrm{~km}$ south of the city, is one of the three water sources for Solapur city; Ekrukh and Ujjani dam are the other two sources. The Bhima river WSS was commissioned in 1964. Water from the river is lifted through a pump set and transported to the treatment plant via Shaft to improve the WTN performance. However, different arrangements have been tried over the years to achieve desired performance from the WTN. The arrangement of the WTN is divided into three Scenarios, as discussed below.

\subsubsection{Case Study 1-Scenario 1 (CS1-S1)}

From commissioning (1964) to 1984, 70 MLD water was pumped to WTP at Soregaon, around $23.0 \mathrm{~km}$ from Takali (pump house location). Water was transported by $1200.0 \mathrm{~mm}$ diameter Mild Steel (MS) pipe. A Shaft of $6.0 \mathrm{~m}$ diameter and $12.0 \mathrm{~m}$ height at Nandani (around $6.0 \mathrm{~km}$ from the pump house location) was constructed to improve the system's efficiency, as shown in Fig. S4. From the Shaft, water was transported through gravity by $1200 \mathrm{~mm}$ diameter pipe till WTP. Three $450 \mathrm{HP}$ vertical turbine pumps were operated to pump the water into the system. Fig. 3a shows the schematic of the WTN between the pump house and WTP of the scheme from 1964 to 1984. Bernoulli's theorem was applied between points 
1 and 2 for RWPM and RWGM (Fig. 3a). The TEL and HGL for the RWPM were calculated using equation 1. As the pipe diameter is the same throughout the section, velocity will be the same at points 1 and 2; hence velocity head gets canceled. At point 2, the pressure will be equal to zero as the water level is open to the atmosphere. As the datum line is considered passing through point 1, the datum head will be zero at point 1. Considering all the parameters, the pressure head at point 1equals the total of datum head at point 2 and the headloss (equation 2). The headloss in the pipe is calculated using Hazen-William's formula with an appropriate roughness factor based on pipe material. A similar procedure was followed for all the scenarios.

$$
\frac{P_{1}}{\rho \mathrm{g}}+\frac{v_{1}^{2}}{2 \mathrm{~g}}+z_{1}=\frac{P_{2}}{\rho \mathrm{g}}+\frac{v_{2}^{2}}{2 \mathrm{~g}}+z_{2}+h_{L}
$$

$P$ is pressure in meters, $v$ is the velocity in $m / s, z$ is the height from the datum line in meters, $h_{L}$ is the head loss in meters, $\rho$ is the density of water in $\mathrm{kg} / \mathrm{m}^{3}, \mathrm{~g}$ is the acceleration due to gravity.

$$
\frac{P_{1}}{\rho g}=z_{2}+h_{L}
$$

\subsubsection{Case Study 1-Scenario 2 (CS1-S2)}

As the demand increased, in 1984, the WTP capacity was increased to 110 MLD. Also, one additional pump at the pump house was installed to satisfy the increased demand. As the pumping increased from 70 MLD to 110 MLD, frequent overflows from the Shaft were reported. Increasing the height of the Shaft was difficult; hence, floats were mounted over the Shaft to avoid overflow of water. The excess water was bypassed to the RWGM. However, this arrangement did not prove useful, as overflow from the Shaft was still prevalent. Finally, the Urban Local Body (ULB) decided to bypass the Shaft and directly pump the water to WTP (Fig. 3b). Hence, the complete WTN was operated as an RWPM, with an additional static head over the pipeline. The impacts of bypassing the Shaft are discussed in the result and discussion section.

\subsubsection{Case Study 1-Scenario 3 (CS1-S3)}

The ULB decided to construct a new Shaft to minimize the static head over the pipeline. In 2015, a new Shaft was commissioned besides the old Shaft. The new Shaft was constructed and operated with $6.0 \mathrm{~m}$ diameter and $22.0 \mathrm{~m}$ height (Fig. 3c). The implications of the new Shaft on the transmission network are reported concerning operational cost and energy grade lines in the result and discussion section.

\subsection{Case Study 2: Shaft at Pise weir Water Supply Scheme, Thane, Maharashtra, India}

Thane city is adjoining Mumbai in Maharashtra. Pise weir is one of the four sources of water supply to Thane city. The WSS of Municipal Corporation of Greater Mumbai (MCGM), Maharashtra Industrial 
Development Corporation (MIDC), and Shahad Temghar are three other water sources. The WSS from Pise weir is designed and operated by Maharashtra Jeevan Pradhikaran (MJP), a state government body responsible for piped water supply in Maharashtra, India. The scheme was commissioned in 1998. Initially, the scheme was able to deliver 120 MLD water from Pise weir to fulfill part of the water demand of Thane city. A $7.0 \mathrm{~m}$ high Shaft was used in the WTN from the pump house to WTP to reduce the static head over the pipeline, shown in Fig. S5.

The details about the pipeline are mentioned in Fig. S6. Post 2009, due to exponential growth in the population, the city's water demand increased drastically. Thane Municipal Corporation (TMC) decided to augment the Pise weir scheme to satisfy the increased demand. A new Shaft was constructed with a change in the elevation. Also, to improve the system's carrying capacity, additional RWPM and RWGM were laid. After augmentation, the scheme was able to deliver 240 MLD of water with three operating pumps and two standby pumps. The impact of change in Shaft location was studied using a single pump operation. Also, a single pipe arrangement was considered for a fair comparison of the Shaft configuration. Accordingly, two scenarios are discussed below.

\subsubsection{Case Study 2 -Scenario 1 (CS2-S1)}

From 1998 to 2009, the WTN arrangement from the pump house to WTP is shown in Fig. 4a. HGL of the Shaft was fixed at $33.5 \mathrm{~m}$, and accordingly, the diameter of the RWPM and RWGM were finalized. A single pump operation delivered 60 MLD through $1244.0 \mathrm{~m}$ diameter RWPM based on the Shaft arrangement. Similar to case study 1, Bernoulli's theorem was applied between points 1 and 2 marked in Fig. 4a to calculate the energy grade line. Also, based on the available data, the operational energy of the system was calculated.

\subsubsection{Case Study 2 -Scenario 2 (CS2-S2)}

The arrangement described in CS2-S1 worked well till 2009. However, as the population of Thane city increased exponentially, to fulfill the increased demand, the use of an additional 120 MLD water from Pise weir was allocated to TMC. Changes in the Shaft dimension and location were done to modify the carrying capacity of the existing system (Fig. 4b). The new HGL of Shaft was set as $28.0 \mathrm{~m}$. The comparison of old and new Shaft with respect to the energy grade line, operational energy, and impact on the system's carrying capacity was carried out.

\section{Results And Discussions}

The impact of Shaft on WTN from the pump house to WTP in the case studies is reported for energy grade line, energy cost, and energy performance indicator in each scenario. Finally, the operational benefits of Shaft in WTN are presented.

\subsection{Energy grade line}


In the case of Bhima river WSS, Solapur, Maharashtra, India, as the demand increased, in 1984, WTP capacity was increased from 70 MLD to 110 MLD by duplicating the components of the WTP (CS1-S1). Also, one additional pump at the pump house was installed to satisfy the increased demand. Due to an increase in discharge from 70 MLD to 110 MLD, frequent overflows from the Shaft were detected. The overflow from the Shaft can be validated by the TEL and HGL, as shown in Fig. 5a. The authority decided to bypass the Shaft and directly pump the water to WTP to avoid Shaft overflow (CS1-S2).

The RWGM was operated as RWPM till the WTP, causing frequent operation and maintenance of the pipeline. The main reason was the static head increase over the pipes (Fig. 5b), which increased pressure and led to leakages and pipe bursts. Additionally, the operation and maintenance of pumps were increased, as pumps were not operated at the design head. ULB replaced around $2.00 \mathrm{~km}$ of the old pipe with a new pipe to manage the system, which was more sensitive to the increased static pressure. Still, the system's overall expenditure on operation and maintenance was higher; the system could not work at its full capacity.

In CS1-S3, a new Shaft was commissioned. Unlike CS1-S1, ample buffer was provided in the Shaft in CS1-S3. The TEL and HGL, as shown in Fig. 5c, confirm the Shaft capacity. In CS1-S3, the Shaft managed to reduce the static head over the pipelines, creating a new static head from the Shaft to the downstream pipeline (Fig. 5c). This reduction in the static head decreased the operation and maintenance of the pipe substantially. After construction of the new Shaft, in CS1-S3, pumps were operated with full capacity to lift 110 MLD water from the source. As the pumps are operated at the desired head, operation and maintenance activity is reduced. The WTN from the pump house to WTP is currently being operated at full capacity, with reduced operation and maintenance.

The application of Shaft at the appropriate location in Pise weir WSS, modified the system's system's carrying capacity. In the CS2-S1, the single pump operation was able to deliver 60 MLD water. Whereas, in CS2-S2, 80 MLD of discharge was possible with modified shaft configuration. Fig. 6 shows the TEL and HGL for both scenarios. As the HGL of Shaft was kept high in CS2-S1, the extra static head can be seen on the RWGM, increasing the operation and maintenance of the pipeline. Also, on the RWPM, an extra pump head was responsible for the reduction in the discharge. In CS2-S2, as the HGL of the Shaft was reduced, the pumping head decreased, changing the discharge from 60 MLD to 80 MLD. Additional 20 MLD discharge was possible in the single pump operation with existing WTN. Also, the reduced static head over RWGM declined the operation and maintenance.

The pump house was constructed to accommodate five pumps. Hence, three additional pumps were installed, and parallel pipes were laid as shown in Fig. S6b. So, with three pumps operating simultaneously, discharge of 240 MLD was possible in CS2-S2. Four pumps would have been required to achieve 240 MLD of discharge, with CS2-S1. Thus, the change in location of the Shaft saved one extra pump requirement without compromising the desired discharge.

\subsection{Life Cycle Energy cost and Energy Performance Indicator}


In both the case studies, the application of Shaft at an appropriate location has improved the system's carrying capacity. The SEC and life cycle energy cost were determined to quantify the benefits of modifications in the Shaft configuration (Table 1). In Bhima river WSS, the SEC reduced from 1.56 in CS1S2 to 0.99 in CS1-S3. Hence, modification in the Shaft configuration reduction of $36.5 \%$ in energy consumption. Also, from the present worth of energy cost calculations, it is clear that savings of 11,898 USD/ML were possible due to Shaft's application. The least value of SEC and energy cost in CS1 is that of CS1-S1 because 70 MLD discharge was considered for calculation, as the system was overflowing for 110 MLD.

In Pise Weir WSS, (CS2), a single pump operation was considered for calculating the SEC and life cycle energy cost in both the scenarios. In CS2-S2, as the height of the Shaft was reduced, a minimal reduction in energy consumption and cost savings was observed (Table 1). However, for 240 MLD of discharge, substantial savings were observed due to the change in the Shaft height. In CS2-S1, four pumps were required to convey 240 MLD of water, whereas in CS2-S2, three pumps are sufficient to convey the same discharge described in Fig. S6. For 240 MLD discharge, the SEC is 0.73 and 0.47 in CS2-S1 and CS2-S2 respectively, suggesting $35.6 \%$ decline in energy consumption in CS2-S2. Further, the energy cost declined from 15,443 USD in CS2-S1 to 9,957 USD in CS2-S2.

Overall, from both the case studies, it is clear that the Shaft with the appropriate configuration can substantially reduce energy consumption and cost. Vilanova and Balestieri (2014) had define various levels of interventions for improving the energy efficiency of WSS. The interventions are classified based on the energy savings resulting due to application of the intervention. Based on the energy savings (more than 30\%), the application of Shaft can be classified as level 2 interventions for energy efficiency improvement of WSS. Additionally, as the construction of Shaft is relatively simple (Kalbar and Gokhale 2019), and it supports the silent features mentioned in Vilanova and Balestieri (2014) like relatively inexpensive, easy to construct, and results in substantial energy savings of level 2 interventions for minimizing the energy consumption in a WSS.

\subsection{Operational benefits of Shaft in WTN}

Based on the learnings from the case studies, the operational benefits of the Shaft in WTN are discussed below.

\subsubsection{Hydraulic separation}

As the inlet of the Shaft is open to the atmosphere, once the water spills from the inlet pipe into the annular space, a water column is formed, responsible for the hydraulics of the downstream network. A new HGL is formed at Shaft, resulting in hydraulic separation between the upstream and downstream sides (Kalbar and Gokhale 2019). The introduction of Shaft bifurcates the WTN into RWGM and RWPM. Gravity-based network performance is always better than a pumped system (Zaman et al. 2021). The hydraulic separation limits the impacts of water hammers from RWPM, resulting in improved efficiency of 
the downstream network of the Shaft. Additionally, the static head over RWGM can be controlled using a Shaft at an appropriate location in WTN.

\subsubsection{Dissipation of water hammer}

Water hammer is a common phenomenon in a WTN. Surge control devices are often deployed to dissipate water hammers. Many studies have described the application and advantages of the surge control device in the WTN (Kim 2010; Zhang et al. 2019). A Shaft can be one of the surge control devices. As the inlet of the Shaft is open to atmosphere, the entrapped air in the pipeline can be dissipated at the Shaft. Removing entrapped air avoids cavity formation in the pipeline, ultimately resulting in a fully pressurized pipeline downstream of the Shaft.

\subsubsection{Improvement in the carrying capacity of the network}

If a shaft with appropriate dimension and location is constructed in a WTN, the pump head can be reduced. As the pump head decreases, the pump can discharge more water. Moreover, the RWPM and RWGM can carry increased discharge with changed velocity until the working pressure on the pipeline is within the permissible limit. Hence, more discharge can be delivered with the same set of pipelines by constructing a Shaft at an appropriate location.

\subsubsection{Reduction in operation and maintenance of pipelines}

An RWPM is always under a high static head, resulting in leaks and pipe bursting, increasing the operation and maintenance expense. As discussed earlier, the introduction of Shaft converts the portion of RWPM into RWGM. The conversion of RWPM to RWGM eliminates the extra static head over the pipelines. Additionally, introducing a Shaft reduces the pumping head; apart from the increase in discharge, the static head is reduced, ultimately reducing the operation and maintenance expense.

\section{Conclusions}

The present work contributed to the quantification of benefits of use of shaft in pumping system. The benefits of Shafts were quantified through operational energy and associated life cycle cost. A pipeline network based on pump supply is prone to water hammer, increased operation and maintenance, and high energy consumption. Although the application of Shaft is commonly found in WTN with varied ground levels, scientific documentation of the use of Shaft on the WTN is rare in the literature. In this study, two real case studies from Maharashtra, India, were selected to quantify the Shaft benefits in WTN. In both the case studies where Shaft was used, substantial energy and cost savings were observed. In addition to energy savings, notable improvement in the system's carrying capacity was witnessed due to the use of Shaft in WTN.

Additionally, application of Shaft in WTN has operational benefits like minimizing the effect of water hammer, thus reducing the operation and maintenance cost of the pipelines. Also, Shaft reduces the extra static head over the pipeline, improving the performance of the system. The Shaft acts as a hydraulic 
isolation structure, separating the hydraulics of the upstream and downstream network. The hydraulic separation, helps in conversion of the RWPM into RWGM. Overall, use of Shaft at appropriate location in the WTN will substantially improve the efficiency of the system.

\section{Abbreviations}

\begin{tabular}{ll} 
BPT & Break Pressure Tank; \\
\hline EPI & Energy Performance Indicator; \\
\hline HGL & Hydraulic Grade Line; \\
\hline MLD & Million Liter per Day; \\
\hline PAT & Pump As Turbine; \\
\hline PRV & Pressure Reducing Valve; \\
\hline RWGM & Raw Water Gravity Main; \\
\hline RWPM & Raw Water Pumping Main; \\
\hline SEC & Specific Energy Consumption; \\
\hline TEL & Total Energy Line; \\
\hline WDN & Water Distribution Network; \\
\hline WSS & Water Supply System; \\
\hline WTP & Water Treatment Plant; \\
\hline WTN & Water Transmission Network
\end{tabular}

\section{Declarations}

\section{Acknowledgments}

The first author acknowledges the scholarship received under the Teaching Assistant Category at the Indian Institute of Technology Bombay by the Ministry of Human Resource and Development (MHRD), Government of India. The authors also acknowledge the funding received under the sponsored research project from the Department of Science and Technology (DST), India - Water Technology Initiative (WTI) - 2017 DST/TM/WTI/2K17/39. Also, the technical discussions with Mr. Pradeep Gokhale, Retired Superintendent Engineer, Maharashtra Jeevan Pradhikaran, Maharashtra, India, helped to bring clarity to this work.

\section{Supplementary Material}

Figs S1-S6 and equations 1-6 are available online in Supplementary Material. 


\section{Data Availability Statement}

The data related to the Water Transmission Network is confidential and may be provided with some restrictions.

\section{Conflict of interest}

The authors declare there is no conflict of interest.

\section{References}

1. Bansal, R. 2011 A Textbook of Fluid Mechanics and Hydraulic Machines, $9^{\text {th }}$ edition, Laxmi Publications, New Delhi, India.

2. Bajwa, G. 2011 Practical handbook on Public Health Engineering, $3^{\text {rd }}$ Edition, Saurabh Publishers, New Delhi.

3. Bohorquez, J., Lambert, M. F., and Simpson, A. R. 2020 Identifying head accumulation due to transient wave superposition in pipelines. Journal of Hydraulic Engineering, 146(1), 04019044. Doi: 10.1061/(ASCE)HY.1943-7900.0001631.

4. Boulos, P. F., Karney, B. W., Wood, D. J., and Lingireddy, S. 2005 Hydraulic transient guidelines for protecting water distribution systems. Journal-American Water Works Association, 97(5), 111-124.

5. Cabrera, E., Pardo, M. A., Cobacho, R., and Cabrera Jr, E. 2010 Energy audit of water networks. Journal of Water Resources Planning and Management, 136(6), 669-677. Doi:

10.1061/(ASCE)WR.1943-5452.0000077.

6. Cabrera, E., Gómez, E., Cabrera Jr, E., Soriano, J., and Espert, V. 2015 Energy assessment of pressurized water systems. Journal of Water Resources Planning and Management, 141(8), 04014095. Doi: 10.1061/(ASCE)WR.1943-5452.0000494.

7. Carravetta, A., Del Giudice, G., Fecarotta, O., and Ramos, H. M. 2012 Energy production in water distribution networks: A PAT design strategy. Water resources management, 26(13), 3947-3959. Doi: 10.1007/s11269-012-0114-1.

8. Coelho, B., and Andrade-Campos, A. 2014 Efficiency achievement in water supply systems-A review. Renewable and Sustainable Energy Reviews, 30, 59-84. https://doi.org/10.1016/j.rser.2013.09.010.

9. CPHEEO. 1999 Manual on Water supply and Treatment. Central Public Health and Environmental Engineering Organization (CPHEEO). Ministry of Urban Development, Government of India, New Delhi.

10. CWC. 2017 Guidelines for planning and design of piped irrigation network. Central Water Commission (CWC). Ministry of water resources, river development and ganga rejuvenation. Government of India, New Delhi.

11. Fecarotta, O., Arico, C., Carravetta, A., Martino, R., and Ramos, H. M. (2015). Hydropower potential in water distribution networks: Pressure control by PATs. Water resources management, 29(3), 699-714. 
doi: $10.1007 / \mathrm{s} 11269-014-0836-3$

12. Jordon, T. D., Jr. 1984 Handbook of gravity-flow water system for small communities. A reference manual for surveying, designing, and constructing gravity flow water system, Government of Nepal, Nepal.

13. Kalbar, P., and Gokhale, P. 2019 Decentralized infrastructure approach for successful water supply systems in India: use of multi-outlet tanks, shafts and manifolds. Journal of Water Supply: Research and Technology-Aqua, 68(4), 295-301. https://doi.org/10.2166/aqua.2019.158.

14. Kalbar, P. P., Gokhale, P. N., Ghorpade, A. K., and Sinha, A. K. 2021 Low Cost Interventions for Improving Water Supply Systems in India. Journal of Indian Water Works Association, Vol LIII (3).174-181.

15. Kim, S. H. 2010 Design of surge tank for water supply systems using the impulse response method with the GA algorithm. Journal of Mechanical Science and Technology, 24(2), 629-636. doi: 10.1007/s12206-010-0108-y.

16. McNabola, A., Coughlan, P., and Williams, A. P. 2011 The technical and economic feasibility of energy recovery in water supply networks. In Proceedings of International Conference on Renewable Energy and Power Quality, Las Palmas de Gran Canaria, Spain (Vol. 1315).

17. Miao, D., Zhang, J., Chen, S., and Yu, X. D. 2017 Water hammer suppression for long distance water supply systems by combining the air vessel and valve. Journal of Water Supply: Research and Technology-AQUA, 66(5), 319-326. doi: 10.2166/aqua.2017.131.

18. Nault, J. D., and Karney, B. W. 2016 Improved rigid water column formulation for simulating slow transients and controlled operations. Journal of Hydraulic Engineering, 142(9), 04016025. doi:10.1061/(ASCE)HY.1943-7900.0001145.

19. Pelli, T., and Hitz, H. U. 2000 Energy indicators and savings in water supply. Journal-American Water Works Association, 92(6), 55-62.

20. Sontake, N. N., Vasudeo, A. D., Ghare, A. D., and Ingle, R. N. 2016 Optimizing the Cross-Sectional Area of the Break Pressure Tanks. Journal of Pipeline Systems Engineering and Practice, 7(2), 06016001. doi: 10.1061/(ASCE)PS.1949-1204.0000234.

21. del Teso, R., Gómez, E., Estruch-Juan, E., and Cabrera, E. 2019. Topographic energy management in water distribution systems. Water Resources Management, 33(12), 4385-4400. doi: 10.1007/s11269019-02375-9.

22. Vilanova, M. R. N., and Balestieri, J. A. P. 2014 Energy and hydraulic efficiency in conventional water supply systems. Renewable and Sustainable Energy Reviews, 30, 701-714. doi: http://dx.doi.org/10.1016/j.rser.2013.11.024.

23. Wan, W., and Zhang, B. 2018 Investigation of water hammer protection in water supply pipeline systems using an intelligent self-controlled surge tank. Energies, 11(6), 1450. Doi: 10.3390/en11061450.

24. Zaman, D., Tiwari, M. K., Gupta, A. K., and Sen, D. 2021 Performance indicators-based energy sustainability in urban water distribution networks: A state-of-art review and conceptual framework. 
Sustainable Cities and Society, 103036. doi: 10.1016/j.scs.2021.103036.

25. Zhang, Y., Liu, M., Liu, Z., Wu, Y., Mei, J., Lin, P., and Xue, F. 2019 Pump-stoppage-induced water hammer in a long-distance pipe: a case from the Yellow River in China. Water Supply, 19(1), 216-221. doi: 10.2166/ws.2018.069.

\section{Tables}

Table 1. Specific energy consumption and present worth of energy cost of the case studies

\begin{tabular}{cccc}
\hline Scenario & $\begin{array}{c}\text { Carrying } \\
\text { capacity } \\
\text { (MLD) }\end{array}$ & $\begin{array}{c}\text { Specific Energy } \\
\text { Consumption } \\
\left(\mathbf{k W h} / \mathbf{m}^{3}\right)\end{array}$ & $\begin{array}{c}\text { Present worth of } \\
\text { energy cost } \\
\text { (USD/ML) }\end{array}$ \\
\hline $\begin{array}{c}\text { Case Study 1- } \\
\text { Scenario 1 }\end{array}$ & 70 & 0.65 & 13,646 \\
Case Study 1- & 110 & 1.56 & 32,812 \\
Scenario 2 & 110 & 0.99 & 20,914 \\
Case Study 1- & & & 3,173 \\
Scenario 3 & 60 & 0.15 & \\
Case Study 2- & & & \\
Scenario 1 & & 0.14 & \\
\hline Case Study 2- & 80 & & \\
Scenario 2 & & & \\
\hline
\end{tabular}

\section{Figures}




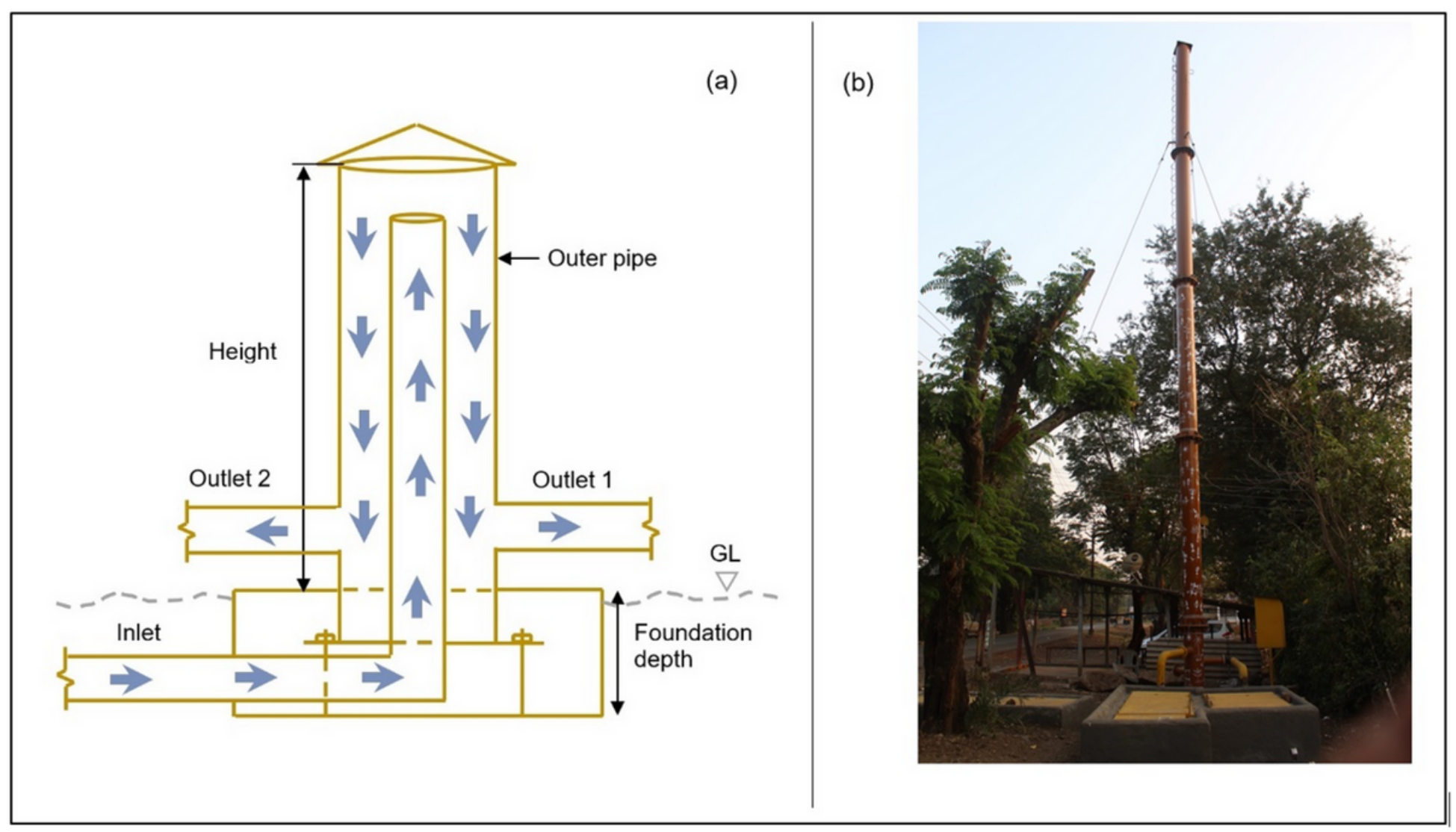

Figure 1

Cross-section of a Shaft (a), Shaft at Saphale, Palghar, Maharashtra, India (b) 


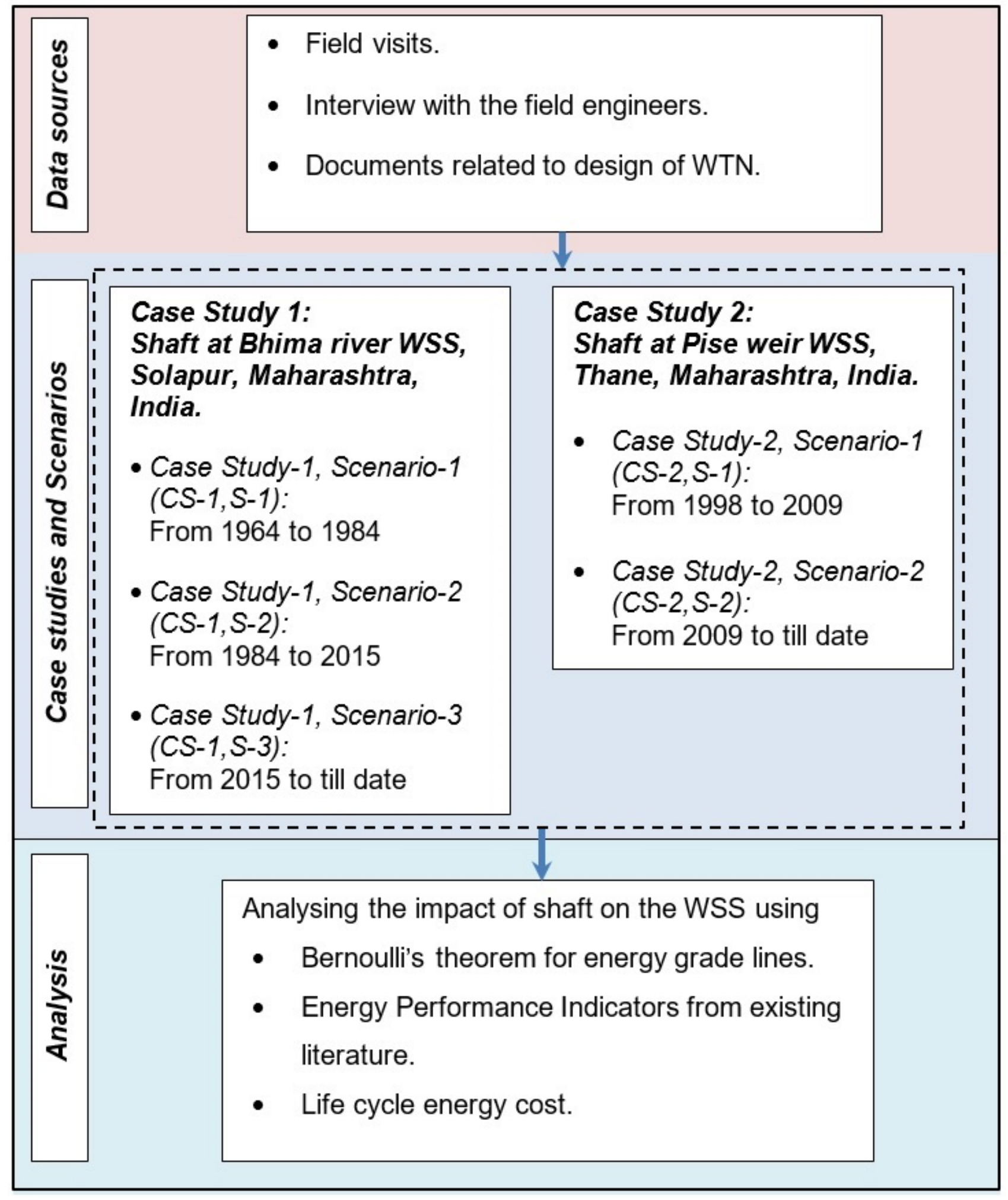

Figure 2

Flow chart of the methodology 


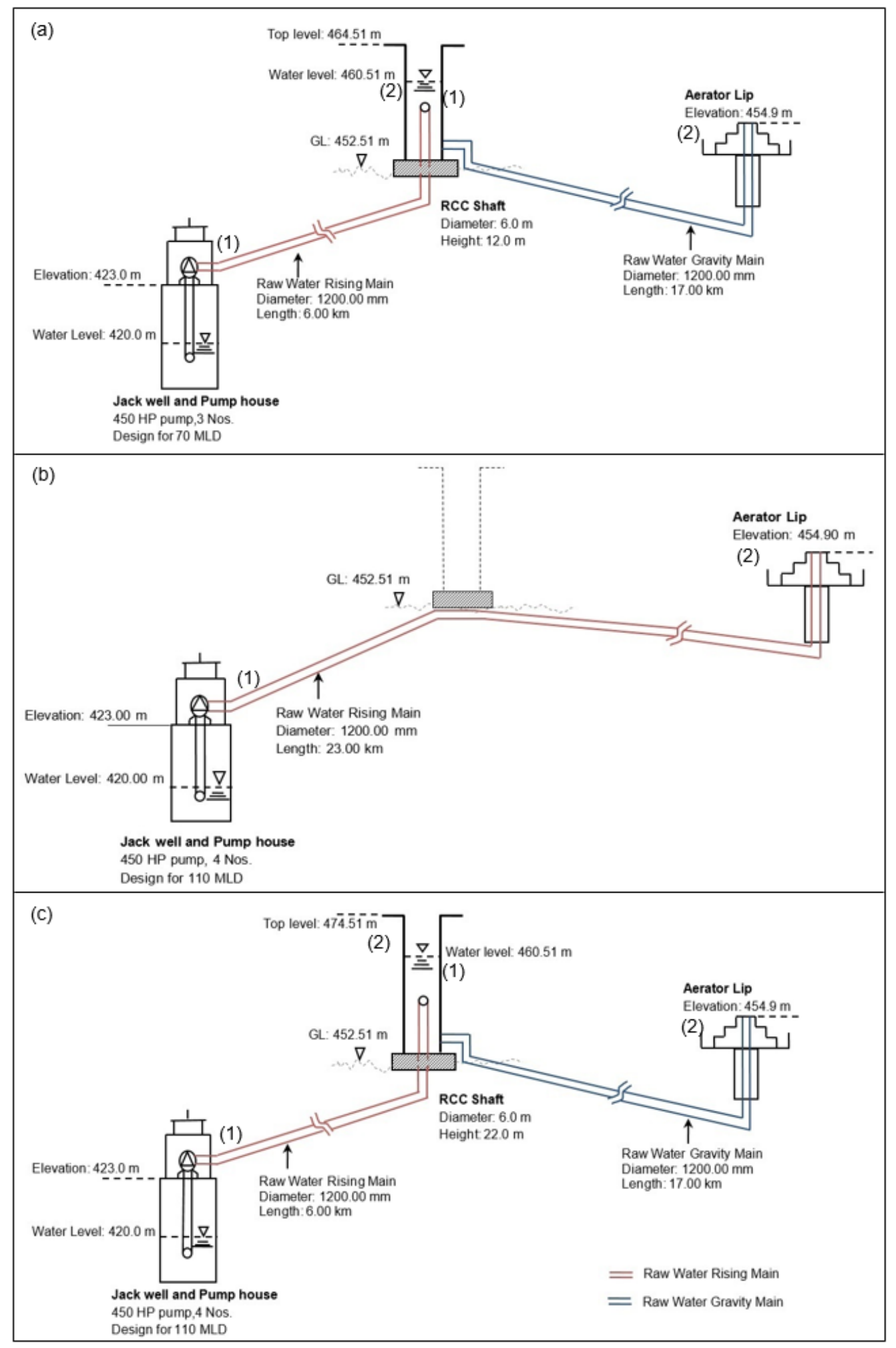

Figure 3

Schematic transmission network between the pump house and WTP of Bhima river WSS, Solapur, Maharashtra, India. (a) Case Study 1-Scenario 1: From 1964 to 1984, (b) Case Study 1-Scenario 2: From 1984 to 2015, and (c) Case Study 1-Scenario 3: 2015 onwards 


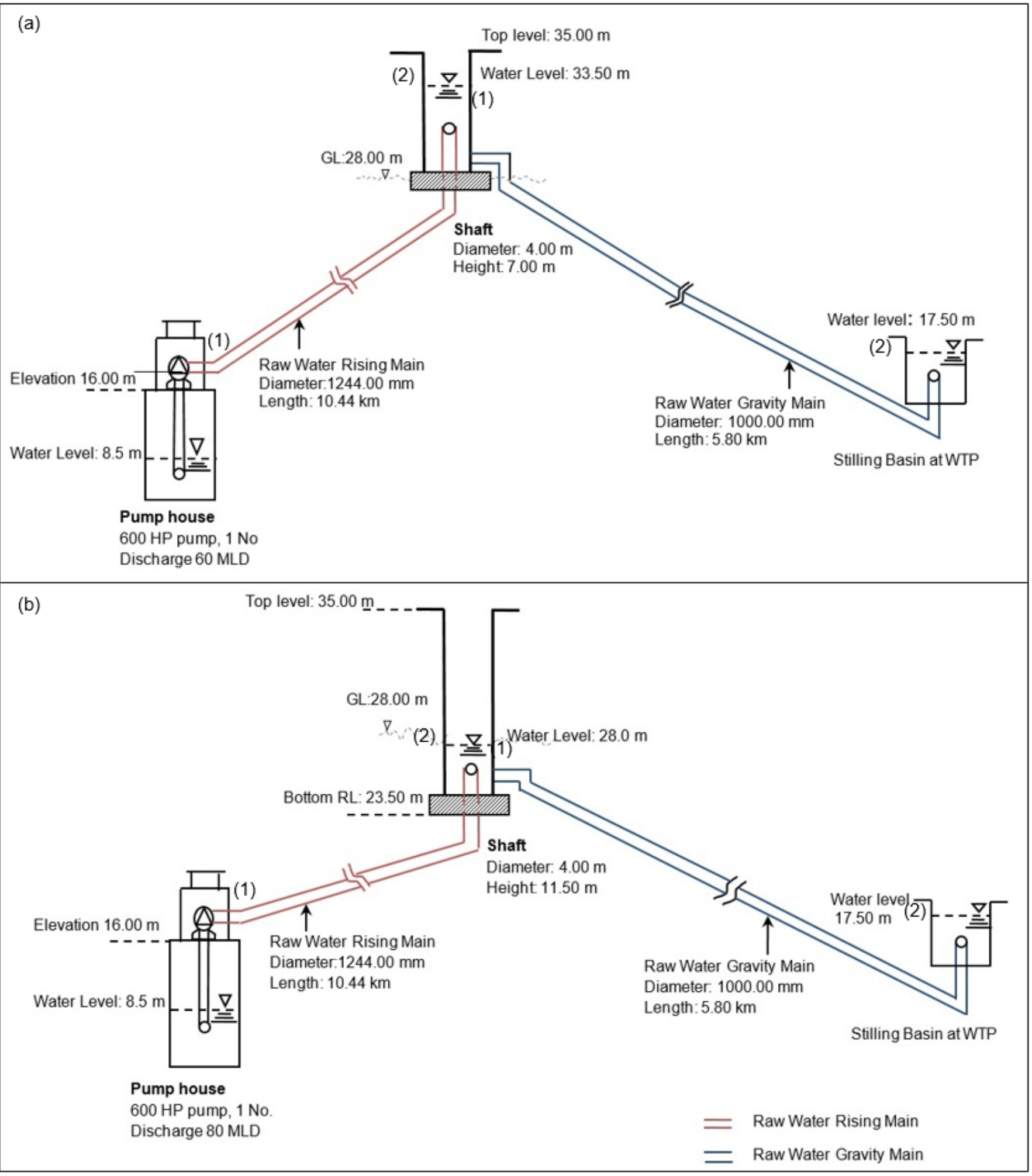

\section{Figure 4}

Schematic transmission network between pump house to WTP of Pise weir WSS, Thane, Maharashtra, India. (a) Case Study 2 -Scenario 1: From 1998 to 2009, and (b) Case Study 2 -Scenario 2: From 2009 onwards 


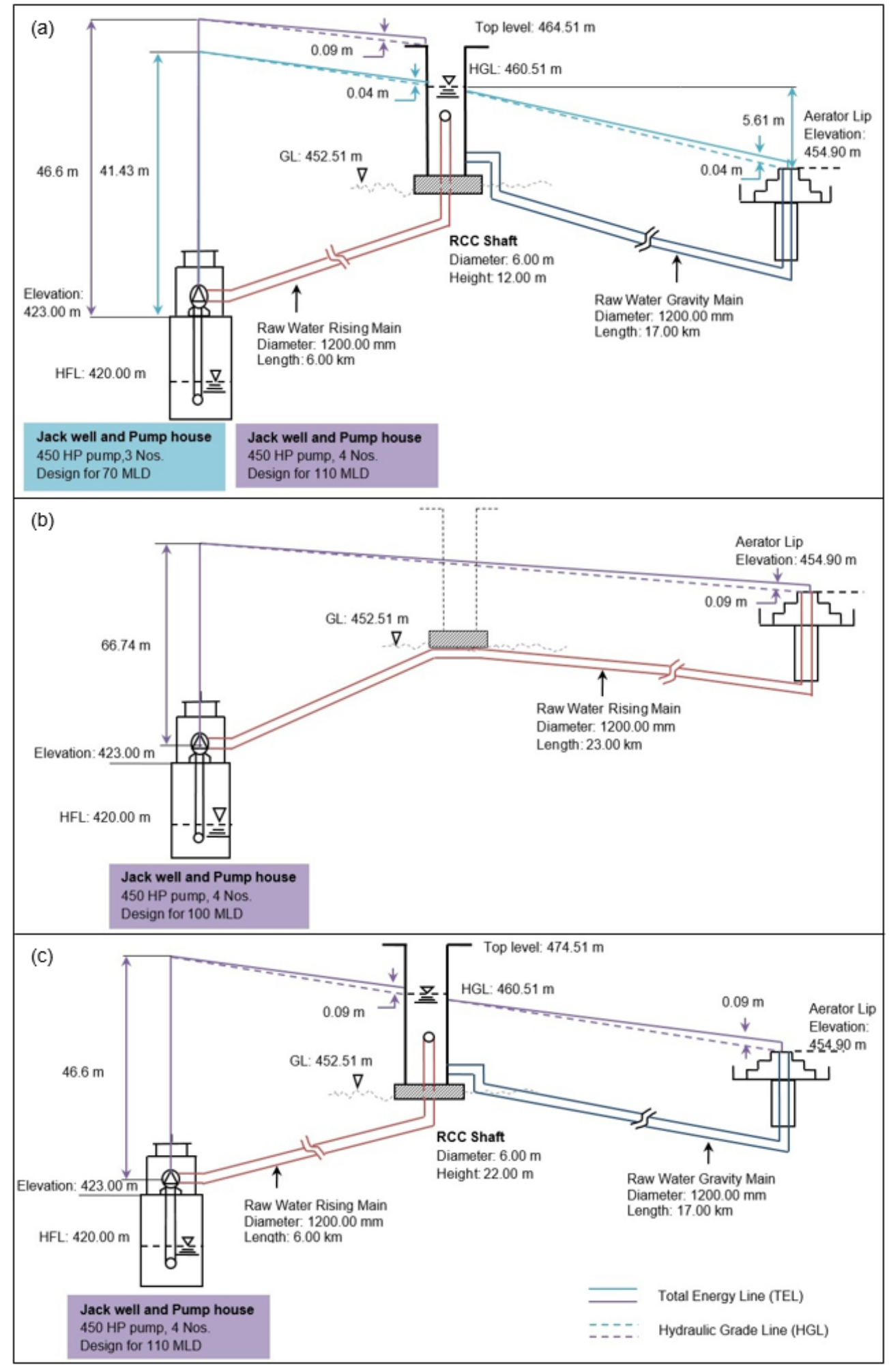

Figure 5

Schematic transmission network between pump house to WTP of Bhima river WSS, Solapur, Maharashtra, India with energy grade lines. (a) Case Study1-Scenario1: From 1964 to 1984, (b) Case Study1-Scenario 2: From 1984 to 2015 and (c) Case Study1-Scenario 3: 2015 onwards 


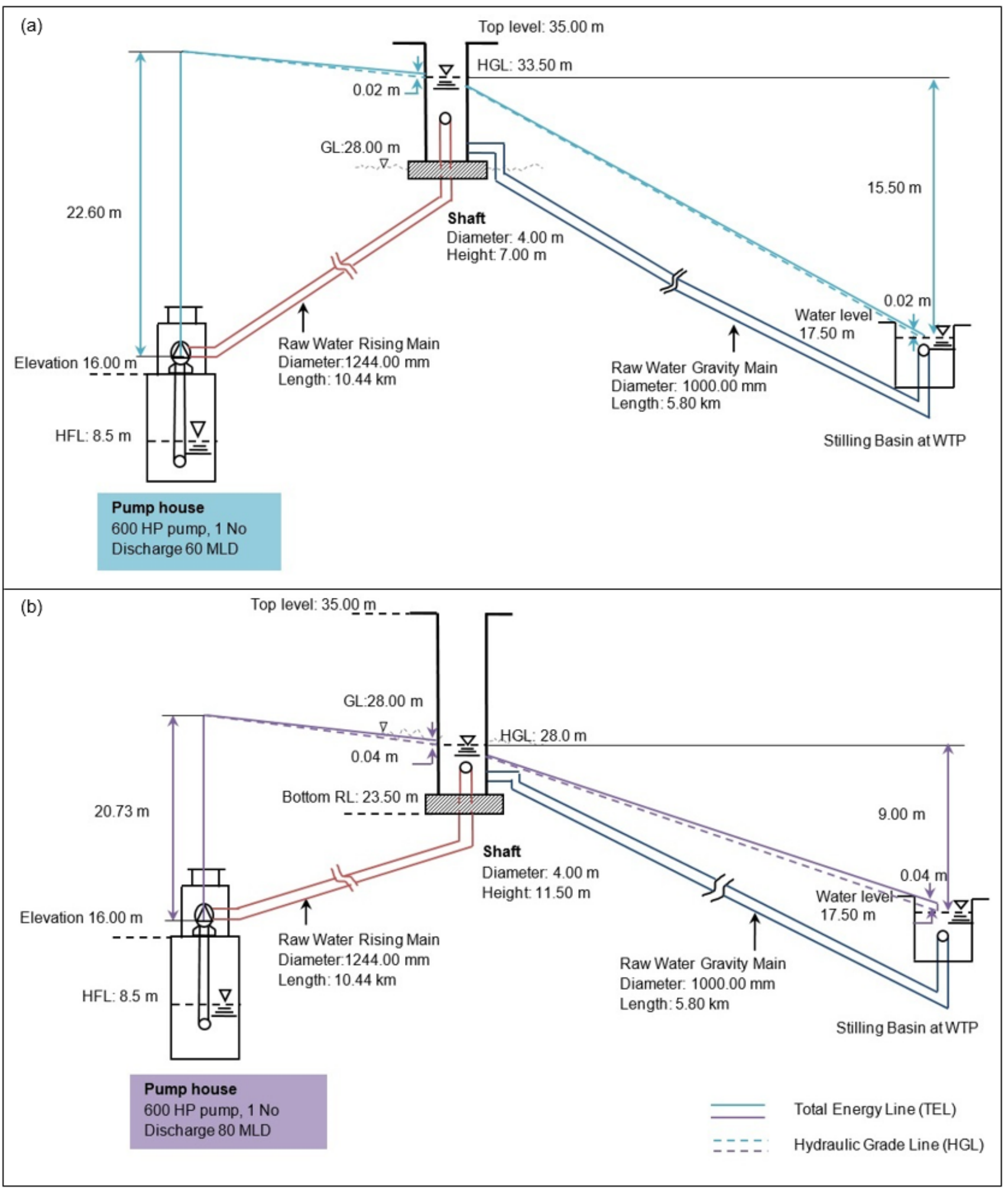

\section{Figure 6}

Schematic transmission network between pump house to WTP of Pise weir WSS, Thane, Maharashtra, India with energy grade line. (a) Case Study 2-Scenario 1: From 1998 to 2009, and (b) Case Study 2Scenario 2: From 2009 onwards

\section{Supplementary Files}


This is a list of supplementary files associated with this preprint. Click to download.

- Supplementarylnformation.docx 